\title{
A teacher education experiment to challenge conceptions and practices
}

\author{
João Pedro da Ponte \\ Instituto de Educação, Universidade de Lisboa, Portugal \\ Célia Mercê \\ Escola Superior de Educação de Santarém, Portugal
}

\begin{abstract}
This study describes a teacher education experience with grade 5-6 teachers, based on a calculator module within a national program for mathematics in-service teacher education. The aim was to challenge the teachers' conceptions about the role of the calculator in mathematics teaching and to promote their reflection about professional practices. The research methodology was qualitative and interpretive, with data collection through interviews and observation of teacher education and classroom supervision sessions as well as analysis of teachers' portfolios. The results indicate that some teachers are clearly against the use of the calculator in the mathematics classroom, others allow students to use it in a passive way, and others are very affirmative about its use. The teachers who argue against the use of the calculator seem to predominate, suggesting a great distance between the curriculum orientations and classroom practice. The methodology of the course, combining collective sessions and individual classroom supervision proved to be fruitful, providing new information, practice and discussion that allowed teachers to analyze different kinds of tasks in which the calculator may be useful, experiment using then in the classroom, and reflect about the students' work. The no imposing and questioning approach used in collective discussions encouraged teachers to assume their own positions and sharing and discussing in the collective reflections during the course stimulated a deeper reflection of their practice. Therefore, in this course, in-service teacher education focused on practice contributed to teachers to reflect on their conceptions and practices.
\end{abstract}

Keywords. Inservice Teacher Education, Mathematics, Calculator, Practice, Conceptions

\section{Introduction}

This study is a teaching education experiment conducted with elementary school teachers that aims to challenge their conceptions about mathematics teaching and to promote their reflection about professional practices. The experiment was carried out as a module centered on the calculator within a national program for mathematics in-service teacher education, initiated in 2005 by the Ministry of Education in Portugal, involving several thousands of participants. Framed by current national curriculum frameworks, this program aims to get teachers to explore different kinds of tasks, from both a mathematical and a didactical perspective, and to reflect on their professional practices, so that they can consider possible changes. As a member of the staff of this program in the school year of 2007-08, the second author of this article was in charge of three groups of mathematics teachers of grades 5 and 6 (who teach students 10-12 years old).

This experiment concerns a teacher education module that addresses the use of the calculator in the classroom. The focus on the calculator was chosen because this instrument has significant educational potential, but generates much controversy among teachers. The fact that a new mathematics curriculum for basic education (grades 1-9) had just appeared in our country, 
recommending the use of the calculator at this school level, implied that the discussion of the role of this instrument become an important issue for teachers.

Rather than encouraging the teachers to use the calculator in their classrooms in a specific way, the module aimed to stimulate them to consider alternative situations in which the calculator could be used in their professional practice, notably in relation to the topic of rational numbers. Above all, we wanted to provide teachers with an opportunity to reflect on why they believed that this instrument should or should not be used in the classroom, taking into account the educational objectives that they value and their view of the conditions necessary for effective use. Teachers were encouraged to think about the possible role of this instrument when their students carry out different tasks and to experiment with using it, as appropriate, in their classes.

In this study, we strive to understand to what extent this exploratory approach, based on a context of professional practice, stressing teachers' activity, discussion and reflection can be used as a strategy for in-service teacher education. More specifically, we want to know how this module influenced teachers' conceptions regarding the use of the calculator in the classroom, how they reflect about such use, and how do they regard this kind of teacher education activity.

\section{Conceptions, professional practices and mathematics teacher education}

Teachers' conceptions and practices. To teach mathematics, the teacher needs a deep mathematical knowledge. Ball, Hill and Bass (2005) argue that such mathematical knowledge assumes two dimensions, knowledge of mathematics (mathematical concepts, processes, representations) and knowledge about mathematics (understanding the nature of this subject). Furthermore, as Ponte and Chapman (2008) indicate, teachers also need other kinds of knowledge related to the specific issues of mathematics teaching, including planning, conducting instruction in relation to curriculum goals, using tasks and resources, handling classroom discourse and evaluating students.

Research has sought to identify the conceptions and practices of mathematics teachers and has shown that their conceptions "are important to understand what teachers do and why they do it" (Ponte and Chapman 2006, p. 477). Teachers' conceptions act as a filter: "On the one hand, they are indispensable, because they structure the meaning we give to things. On the other hand, they act like a blocker in relation to new realities and to some problems, limiting our possibilities for acting and understanding" (Ponte 1992, p. 1). Therefore, conceptions have a double role - they are essential so that the teacher is not lightly swayed by each new theory or idea, but they also make teachers resistant to change, inhibiting them from evolving and from adjusting themselves to the current requirements of mathematics teaching.

Thompson (1992) argues that the way teachers teach mathematics is related to their conceptions. She suggests that there is an interaction between conceptions and practices, as teachers' conceptions tend to induce particular practices and teachers' practical experiences have implications on their conceptions. However, she cautioned that sometimes there are noticeable discrepancies between the views expressed by teachers and their teaching practices. In her view, there are teachers who interact with their environment without entering into conflicts, or learn to live with unresolved conflicts, whereas others strive to respond to the pressures and constraints that limit their professional practice in an active way. That is, tensions between teachers' conceptions and practices may be dealt with in many different ways. 
Regarding the use of the calculator, Assude (2006) argues that there are different kinds of factors that may influence teachers' practices: (i) symbolic, related to the perspectives about learning mathematics concepts of in the early years, often associated with multiplication tables and paper and pencil algorithms; (ii) social, as many parents and teachers feel that when using the calculator students no longer know how to calculate; (iii) ethical, because the development of critical thinking of students, regarding the use of a calculator, induces a greater responsibility in the choice of calculation tools, giving them more autonomy, which can create problems for the teacher; and (iv) personal, because teachers may not know what tasks to offer students or are in the contingency of having to make major changes in their teaching practices.

Teacher education and its impact on teacher practice. Teacher education must have an impact on teachers' practices in order to also impact on students' learning. Therefore, we consider the role of teachers' practices in teacher education, in order to support teachers' professional development. Collective reflective processes allow teachers to interact with other teachers and feel supported in questioning and changing their practices. However, change is also an individual process, dependent on the personal decisions and sense of responsibility of each teacher. So, opportunities must be given for teachers to get in conflict with themselves and with their teaching practices, redefining, if necessary, their professional perspectives.

Ball and Even (2009) indicate that teacher education experiences, viewed in a logic of professional development, must occur in contexts of practice. This is the only way such experiences allow teachers to examine their practices and to develop the ability to innovate them. Therefore, the daily work of the teacher in the classroom becomes the focus of the work carried out in teacher education. Through the consideration of practice, teachers may develop an understanding of instructional issues, of pedagogy and of students' learning processes. This type of teacher education based on teachers' professional practice may start from particular situations, such as tasks with students' productions, videos and episodes of classroom teaching. As Smith (2001), argues, such situations are a powerful means to "help teachers develop the ability to view specific events that occur in the practice of teaching as instances of a larger class of phenomena" (p. 16).

As Perrin-Glorian, Deblois and Robert (2008) indicate, research shows that it is difficult to change mathematics teacher practice and deep changes take a long time. Opportunities for such changes are provided when teachers reflect on their daily practices, examine new practices, and learn more about their students (Ball, Hill and Bass 2005). These opportunities are potentially rich in collaborative settings, where teachers discuss issues arising from practice, where they identify weaknesses and needs and build new knowledge. More than providing teachers with information concerning some mathematical concepts, a theory about teaching and learning or even about strategies and teaching methodologies, such opportunities may provide them with a means for reflection that may lead to changes in teaching practices.

However, teacher education has to combine in a suitable way quite contradictory processes (Ponte 2009). The design of teacher education experiences must be based on an assessment of what teachers need and want to learn as well as what knowledge, skills and experiences they have. As Smith (2001) indicates, usually, teachers show satisfaction in working sessions where they explore some practical activities that they feel they can easily apply to their students and show discomfort with the sessions that address aspects of their practice or provide experiences that cause some internal conflict. The sessions that challenge teachers in their conceptions may leave them not so pleased, but may have a greater impact on their knowledge, conceptions and 
practices. Therefore, a suitable combination of different kinds of experiences is necessary in teacher education.

\section{The teacher education program}

\subsection{Main principles and working dynamics of the program}

As part of an already established national teacher education program, the calculator module was based on the general principles of this program (Serrazina, Canavarro, Guerreiro, Rocha, Portela and Saramago 2006). These principles recognize teachers' classroom practices as a starting point for teacher education and pay special attention to the practical needs of teachers in relation to their curriculum practices. A strong emphasis is also put on collaborative work among teachers.

The course had 15 group sessions spanning all the school year. The topics addressed were referred to the Portuguese curriculum documents and were adjusted according to the interests and needs identified in each group of teachers. The sessions lasted for three hours each, were held fortnightly in a school for each group of 8-10 teachers, and were conducted outside the teachers' normal teaching schedule. Each module of this course included three components closely related. The first involved work on mathematics topics, with planning of tasks to be proposed in teachers' classes. These sessions sought to meet the needs of teachers and the themes were selected so that they could develop their mathematics and didactics knowledge. In these sessions, the calculator was always available for possible use in relation to the topics addressed. The second component referred to the implementation of the planned tasks in classes conducted by the teacher and supervised, in a sympathetic way, by the teacher educator. As teachers proposed the tasks in the classroom, their mathematics and didactics knowledge was put into action. The presence of a teacher educator/supervisor in the classroom helped to better understand the difficulties experienced by teachers and also allowed the collection of information for further discussion and reflection. Finally, the third component consisted of individual and collective reflection on classroom practice. The classroom activity was discussed right after each class by the teacher and the supervisor and, in some cases, was also discussed later by the whole group, in order to promote the professional development of teachers, based on their own practices.

\subsection{The calculator module}

The calculator module had four sessions, held between December 2007 and February 2008, during which the use of this instrument was analyzed in relation to teaching and learning rational numbers. Such analysis was based in the four ideal types of use of the calculator identified by Ruthven (2009) in Project CAN: (i) "computation-implementing", in computations involving large numbers or when it is necessary to do several computations in sequence or in investigating patterns; (ii) "result-checking", in verifying computations already done and in understanding the structure of numbers and operations; (iii) "trial-improving", in promoting mental computation and estimation skills; and (iv) "structure-modelling", in which the computation done in the calculator supports learning some subject.

This module had the following specific objectives: (i) to promote discussion among teachers about the changes in approaches and teaching methods that are associated with using the calculator in teaching practice; (ii) to lead teachers to identify different ways the calculator can 
contribute to mathematics learning; and (iii) to contribute to teachers' reflection on teaching practices in relation to the use of the calculator in different mathematics topics.

The four sessions included moments of discussion in pairs and in whole group, supported by tasks and/or curriculum documents that address mathematical and didactical knowledge related to teaching and learning of rational numbers, with a special attention to the use of the calculator in this topic. These sessions were designed to enable deepening of the mathematical knowledge necessary to teach the curriculum and to develop classroom tasks, taking into account the possible uses of the calculator. Each group session consisted of three moments:

1. Reflection of the tasks previously implemented in the classroom. There was an initial discussion that was based on an analysis of students' productions and classroom episodes registered by the teacher educator or by other teachers of the program. We wanted teachers to develop a self-questioning attitude regarding their practice and its consequences in students' mathematical learning. The role of the teacher educator, at this point, was to question the practices of teachers.

2. Deepening teachers' mathematics and didactics knowledge. Given the professional experience of teachers, practical activities and discussions were promoted, relating mathematics and didactics knowledge.

3. Preparation of the tasks to propose in the classroom. Possible tasks to assign to students in the classroom were discussed, according to proposals presented by both the supervisor and the teachers.

Every session followed these three moments, providing the teachers the opportunity to explore the calculator as a source of problems and exercises, as a tool whose operation and functionalities one seeks to understand, as a computation instrument, to develop number sense, to reinforce writing skills of whole numbers and decimals, to support the exploration of numerical phenomena, to assist in estimation and mental computation, and to understand operations. These sessions followed a plan, exploring the different aspects of the calculator (see Table 1). The teachers worked on different kinds of tasks - some intending to illustrate different possibilities for using the calculator and others aimed at provoking the kind of "disequilibrium" referred by Smith (2001) that may have a strong impact on their knowledge, beliefs and practices. At the end of each session, the teacher educator reflected about the issues to put greater emphasis in the subsequent sessions.

In parallel with the whole group sessions, there were supervision sessions in which the teachers put into practice the tasks collectively planned, keeping the responsibility of organizing and coordinating the classroom work. After each class there was an analysis and reflection by the teacher and the supervisor. Each teacher was supervised in the classroom twice before the calculator module and twice after this module.

The participation of the supervisor in the classroom included moments of close observation when she sought to understand more deeply the work that students were developing, or when, at the end of the class, there was opportunity to exchange ideas with the teacher regarding what happened. There were also moments of intentional distancing of the supervisor, in order to help her broaden the scope of understanding and analysis of different situations. At the end, there were always moments of systematic reflection, supporting the teachers to question themselves and to think about their actions. During the lessons the main focus of attention of the supervisor 
were: (i) the nature of the proposed task, (ii) the classroom organization, (iii) the activity of the student and the teacher, (iv) the written mathematics productions of students, (v) the use and exploration of material resources including the calculator, and (vi) relevant episodes. The supervision sessions were used to detect aspects less consolidated in collective sessions, to help overcome what the teacher felt as weak points, and to collect information to support individual reflection with the teachers and the reflection in the collective sessions.

\section{Research methodology}

This study follows a qualitative and interpretative approach (Bogdan and Biklen 1982). It draws on the interpretive paradigm as its main concern is to understand how participants regard the situation (Patton 1987). Qualitative data was collected from multiple sources - participant observation in collective sessions, non-participant observation in supervised classes, interviews with teachers, and analysis of portfolios.

The participants were 26 teachers belonging to the three teacher groups who attended for the first time this national teacher education program in the district of Santarém. The groups had between 8 and 10 teachers, all with professional experience, and were geographically distant from each other. Group A consisted of teachers from the same school, mostly men, averaging 21 years of teaching experience. Group B was composed of teachers from three schools, all women, averaging 15 years of experience. Group C consisted of teachers of two schools far apart from each other, mixing men and women, with an average of 17 years of experience.

Data was collected during the training program sessions by audio recording. Since the second author was also the teacher educator, participant observation during the program collective sessions (with notes taken afterwards) and the classes supervised (with notes taken on the spot) provided further data of the teachers' conceptions and practices regarding the use of calculators. After the calculator training module, four teachers were interviewed (Alice, Anabela, Clara and Marta), representing a variety of viewpoints regarding the use of the calculator. In addition, we analyzed the 26 portfolios of teachers with special attention to references about the use of the calculator and their thoughts about the teacher education program.

The data collected - oral and written discourse - was subject to discourse analysis (Roth 2005). We established a descriptive corpus addressing the three major topics that frame this report: (i)Teachers' views on the use of a calculator; (ii) Reflection about the use of the calculators in the classroom; and (iii) Views about the calculator module and other teacher education experiences. The analysis of data begun with the four teachers that were interviewed, according to an inductive process, seeking to interpret it with reference to the issues identified in the literature. As a result, several themes were identified and, for those more closely related to the topics addressed in this paper, the corpus of data for the all 26 teachers was subject to new scrutiny. Six major issues were identified (computational skills, use of the calculator in the classroom, getting surprised, breaking fears, rising doubts, strengthening convictions, working processes, positive environment) and, for each one, contrasting views were searched for, in a thorough way. In this analysis, the major concern was with the interpretation and analysis of the processes experienced by the participants, their intentions and meanings in relation to their professional contexts. 


\section{The starting point}

To understand what when on in this course, some glimpses of first collective session are necessary. They provide some idea of the issues discussed, the working environment, and the relation among participants. This session provided many important elements about the teachers' starting point regarding the use of the calculator.

In this session, the following task (adapted from Swan 2001) was proposed, involving the analysis of an instructional episode:

A - In a clothing store there are t-shirts that cost $44.50 €$ and are now with a deduction of $20 \%$. Ana decided to buy two t-shirts and found, after doing some calculations that it would pay $53.40 €$. When he reached the box the wizard asked for $71.20 €$. Ana was very confused. So, who is right?

B- Analyzing the records made by students, identify the strategies that they used and the mathematical knowledge employed.

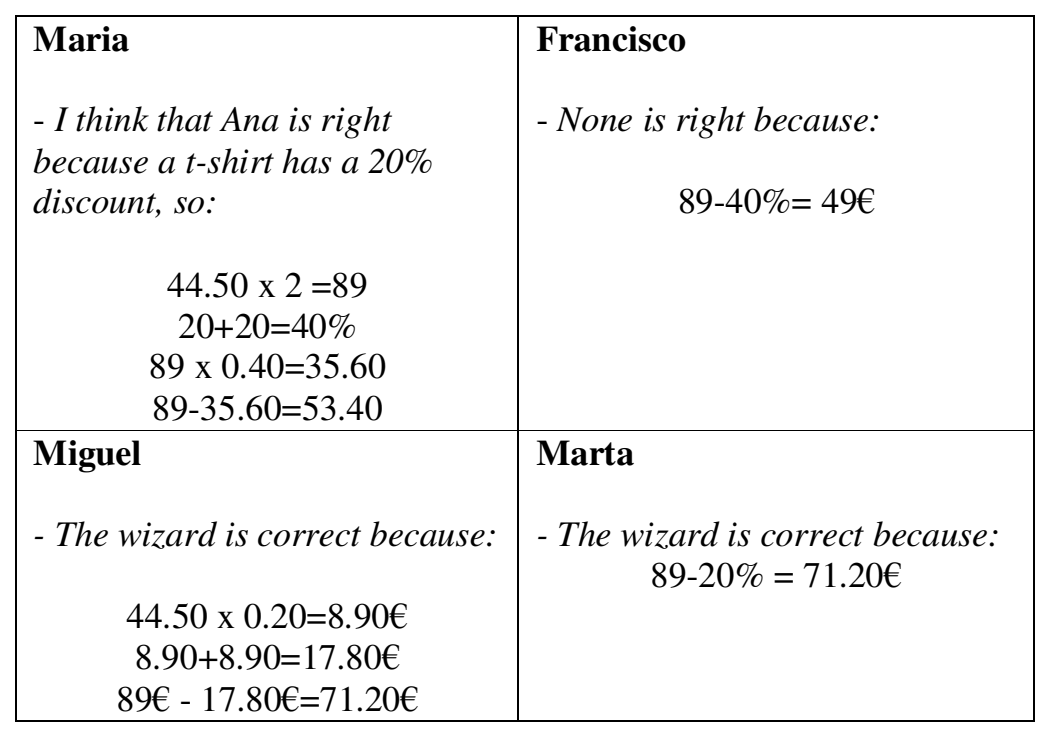

C - In your role as a teacher, how would you deal with the mistakes?

The teachers were asked if they considered it appropriate to use the calculator. The teacher educator did not express her opinion, so that the teachers could express their views without knowing what she thought. In one group, as we expected, the discussion began with the response of one student (Marta). Most teachers did not realize how she got the result:

Sónia: No, she [Marta] has nothing to do with Francisco (...) She did not indicate correctly the problem, so, if she got 71.20 , it is because she had to do $20 \%$ of 89 .

Anabela: But is not what is here.

Sónia: Okay, this is what I am saying. She put not the correct indication.

[Lot of talking]

Teacher Educator (TE): But how does she do 89-20\% and get 71.20? 
Sónia: She did with the machine.

[Lot of talking. Sónia takes a calculator and does computations]

Sónia: Oh! The machine was roguish. If she put this here on the machine she gets 71.20 right away.

Anabela: Oh, yeah. [Confirms in the calculator]

Sónia: I, by chance, was not sure if this would work.

Marta: What?

Sónia: If we put $89-20 \% \ldots$

Marta: But, that... She stopped using the percent technique.

[Confusion among teachers, some seeming outraged by what the student did]

Sónia: Yes, Marta, she made with the machine.

Marta: And can we consider this right? We cannot from a price take a percent with minus. Unless on the machine. [She seems confused with the situation]

Sónia: Unless on the machine. But the machine is a valid instrument.

In this group, the teachers do not foresee the possibility of a student calculating the percent using the \% key, because they did not know its function. Thus, they experimented with the calculators in order to understand how these operated. One teacher, trying to understand the reasoning of the student who wrote $89-20 \%$, takes a calculator from her table and says: "Look, I do not know where is ON. Oh, I and the machines... This should have been 89-20\%, okay". The following dialogue between Maria and Alice shows that they do not agree with the use of the calculator in this task and also that they did not know some aspects of its operation:

Maria: Oh, the machine gives this result? [She laughs at the same time that she experiments].

Alice [Ironically]: ... Machines are spectacular!

Then, the teachers discuss how the student recorded the computation done in the calculator (89$20 \%$ ). At this point, a discussion on the use of the calculator in computing percents begins: How must the calculator be used? One may accept that students compute percents in this way?

TE: Marta is raising an issue that we must discuss. Can we let the students calculate in the machine, in this way $-20 \%$ ?

Sónia: We can. Why not?

Maria: I teach first without the machine and then with the machine.

TE: And when Maria teaches with the machine you do this way $-20 \%$ ?

Maria: No, I do multiplying.

TE: Why? Why do you do it?

Maria: Because I think that it's easier for them to visualize it.

Sónia: The machine has a process, we have not seen it, and if they learn to do this way $(-20 \%)$ they do not learn the notion...

(...)

Marta: But if that was with a student of mine... This year, I will let them use machines. I thought that he did it in a random way, that he had got it wrong and put that. 
Sónia: From the moment you let use the calculator, they can use the calculator, [if] she does this in the calculator, it is because she can use [it that way].

Ana: I do not let them do so. They have to go through multiplication.

TE: Why?

Ana: Because at some point they do not realize what they are doing.

Many teachers expressed doubts and fears. They do not allow students to use the percent key to solve problems, only the use of the multiplication key. Also, they consider that the use of the calculator is an obstacle to a rigorous mathematical record. There are teachers who feel that explaining the students how the machine works means to spend time on issues of little importance compared to the "syllabus that we have to cover". Asked whether they consider it to be appropriate that their students use the calculator on this task, they all agree with that, provided that they were not allowed to use the \% key.

In another group, the discussion was very heated. Some teachers said that they ban the use of the calculator, others leave the choice of using it to students and others lay down rules for its use. Also, in this case, most teachers do not know how the calculator operates, even many of those who said that they let the students use it.

The teachers' opinions in the first group are very homogeneous, with only three teachers receptive to the use of the calculator. Marco, for example, raised many issues:

What I notice is that often students reason, "I have to do this operation", they do not even bother to indicate the operation that they will need to do, the first thing they do is the operation in the machine, "I already have the result", but then, at some point, they are lost and then it gets messed up, because they got lost, the tendency is not to think, "now I'll do this operation and will indicate, and then I have to do... I'll indicate and I do and then I have all the reasoning and I reach a logical result", no, they think on an operation and, bang! immediately they do it.

Alice seems to speak on behalf of all senior teachers. For her, it makes sense that students in grades 5-6 do not have a regular contact with the calculator, as in the following grades students have time to explore it in the classroom. In her view, this is the school level where students learn basic mental and written computation techniques:

I'm pretty sure that if I let them use the calculator as they wish they would do all the computations, $\mathrm{x} 2, \mathrm{x} 5$, even $\mathrm{x} 0$. I'll never forget one time I took a rug for washing that was $1 \mathrm{~m}$ by so many centimeters and it was a young girl and she calculated the area in the calculator multiplying by 1 and (...) I see some of my students doing $1 \mathrm{x} 0 \ldots$ (...) So they have to develop their computation skills.

The first session was important to show that the calculator module could provide teachers with experiences in which the calculator would be used with many purposes, not just for computation. It also showed that the tasks should not be given to teachers ready to be used in the classroom, but in a way so that they could reflect on them, relate them to the curriculum guidelines, design questions for students and think in ways to manage time in the classroom, making connections with other mathematical topics. 


\section{Results}

\subsection{Teachers' conceptions about the role of the calculator in mathematics teaching}

Computational skills. At the beginning of this course, the conception that the mastery of computation skills is an essential part of learning mathematics was very strong among the participating teachers. This means a vision of mathematics teaching focused primarily on doing algorithms and procedures and using techniques for solving problems. Only six teachers were clearly favorable to the use of the calculator in the classroom, but, when they accept the use of this instrument, it appears largely associated with tasks that Ruthven (2008) identifies as computation-implementing, that is, computation involving large numbers or performing various computations in sequence. Only one teacher (Clara), appears to take into account the four areas indicated by this author.

This course provided opportunities for participants to see mathematics teaching in a different way, giving more importance to reasoning and problem solving processes. For example, Alice acknowledges that the tasks that she worked in the course are very different from those that she usually presents to her students in the classroom and in tests, which tend to require a more direct response: "I have the notion that we are very much used to doing like this on tests, applying this specific content that we teach in class and in same way we do in class". Other teachers, like Anabela and Marta indicate that they developed a new appreciation of mental computation, a topic that was the focus of one of the sessions of the calculator module. Marta recognizes that she began to ascribe less value to the importance of algorithms in mathematics teaching:

For example, I had... Mental computation was always my problem [as a student]. I am a person, maybe because of my education, very attached to the algorithm... And I find gradually freeing myself from the algorithms and doing schemes and [doing tasks] more through mental computation. Now, I give more value to mental computation and also to develop it in students. And the course helped me a lot in this regard.

Use of the calculator in the classroom. Eva and Victor, during pre-service teacher education had some contact with the calculator, and had a positive perspective regarding its use in the classroom. However, due to its invisibility in textbooks and as the negative attitude of the teachers in their schools, they ended by considering that its use was not much important. They recognize that they enriched their knowledge about the ways in which the calculator may be used in the mathematics classroom, as the same occurred with other teachers in the course. For example, Marta recognizes that she learned that the calculator may have multiple roles and that it may be used in different ways, not just as a replacement of the written algorithms: "It freed me [of the ideas that I had] and also I learned how to use it in different ways, do you understand? I was just thinking about algorithms... But we can use [the calculator] in different ways". Another teacher, Anabela, values the tasks in which the calculator is used in exploring regularities and acknowledges that she never thought of using it in this way: "No. If I ever thought about it?... No". Finally, Alice says that the course made her rethink the use of a calculator in the classroom. Seeing this instrument explored in different ways led her to recognize that a greater use may make sense, particularly when the learning objectives are interpreting the problem or reasoning about it:

Seeing the [students'] daily difficulty in computation I see myself internalizing that this, in fact... It will not be... [A problem easy to solve] Maybe I'll have to change somehow (...) Maybe, in some classes, in some situations, where we see 
that it is not worth to press [the students] because they do not move on, maybe it is worthier to work the other also important part [interpretation and reasoning], isn't it? More precisely, [the students must] reason, must interpret the statement in that particular situation and the computation they make it on the calculator. (...) Maybe it makes sense, maybe I'm already a little more flexible...

Clara is a teacher that stands out from the other participants. She regards herself as very close to the ideas discussed in the course regarding the teaching of mathematics and, in particular regarding the use of the calculator. In her perspective, the center of mathematics learning is not doing of computations but reasoning with the mathematical ideas and the principles and processes that underlie them. So, this course, more than contributing to her change, reinforced her ideas.

Summary. There seems to be a relationship between the way teachers see the use of the calculator and the importance that they attribute to it and their perspectives on mathematics teaching and learning. The need that they feel in using calculator with their students is related to the type of mathematical experiences that they offer them and the purpose with which they do, which, in turn, is related to what they value the most on mathematics teaching.

The course seems to have contributed to the participating teachers to question the type of tasks that they usually propose to their students, broadening the range of mathematical concepts and processes that they give attention (such as exploring regularities and doing mental computation). From a starting position of great reservation about the use of the calculator, several teachers began to admit that this tool is useful on some occasions, helping to achieve certain objectives. For teachers who already had a teaching perspective aligned with current curriculum orientations, this course seems to have contributed to strengthen their position.

\subsection{Teachers' reflections on their practices}

The teachers that participated in this course showed wide range of practices regarding the use of the calculator. Their reflections regarding their practices on the use of the calculator are in close relation to their professional environment and their views about mathematics teaching.

Getting surprised. Interesting reflections are those in which teachers indicate surprise with what students were able to do. For example, in a collective discussion of a task involving patterns, Eva indicates: "The use of the calculator enabled students to do quickly a computation to discover patterns and find a rule. The calculator was a computation device that facilitated getting the results". She was also surprized with the fact that some of her students did not know how to use the calculator.

Another teacher, Victor, used the calculator with his students in a task involving rational numbers. This task consisted in doing a multiplication (17 times 2.25) in which the students could use the calculator, but with the condition of not touching the $\times$ key. Most students begun to compute, with paper and pencil, the product and, from the result they sought to find a strategy using another operation. Some students, after computing and confirming the result in the calculator, wrote the sum, with 17 addends, to their worksheet, and computed with the algorithm, showing more trust on the computation done in paper and pencil than on the calculator. In this class, a student finds a way to add this long sum on the calculator, entering $2.25+2.25$ and then pressing the $=$ key 16 times. All students tried to do the same on their calculators. Then, there was a classroom discussion about the situations in which it is possible to substitute addition for multiplications and vice-versa. For this teacher, the class went beyond his 
expectations, as he did not believe that his students could develop such a discussion about numbers and the effect of operations: "This task enabled me to observe, talking with the supervisor and reflecting, that the calculator may have a very wide use in classroom situations and encouraged me to increase its use".

Breaking fears. Anabela, during her pre-service teacher education, learned about the use of the calculator in mathematics teaching. In her eight years of teaching practice she often used this instrument. However, in their current school, the calculator is not well regarded by her colleagues. In this adverse environment, she stopped using it. She justifies not using the calculator in her classrooms also by lack of time, lack of machines available and the added complexity to classroom management, but what seems to stand out in this teacher is a social influence (Assude 2006), caused by the school professional culture. At the end of the course, she expresses a favorable view of the use of a calculator in the classroom and indicates willingness to do it regularly:

[The course] confirmed what I thought is useful and that there are many people who really do not understand, I think, do not understand the utility that it [the calculator] may have, because they see only the dangers and I think that, if well used, it may be very helpful.

Marta also indicates social influences from her colleagues in her school. She notes that the course brought her security to use the calculator in the classroom and now she intends to invest much more in the exploring its potential:

[It] helped me to break my fears regarding the calculator (...) I did not feel at ease to use the calculator because I saw that my colleagues also do not... (...) It freed me a bit, you understand? And besides, I also learned how to use the calculator on some problems such as [searching for] regularities and patterns... And I have the tasks set aside and it may not seem but I get home and I look at it again and I experiment...

Rising doubts. Another teacher, Alice does not accept the calculator in her practices, considering that in the early years of school written and mental computation should be developed first. Her experience as a student marks the way she values memorization and written computation. Her fear regarding the use of the calculator is related to the dependence that she considers students may create, losing their computation skills. In this teacher we note the influence of symbolic factors (Assude 2006), related to her conception of mathematics teaching, with emphasis on multiplication tables and paper and pencil algorithms. She also depicts social concerns, considering that, if her students use the calculator, they may no longer know how to calculate. She also thinks that the tasks to propose using the calculator will require major changes in her teaching practice, which leaves her uneasy, fearing that she will not have time to cover all the syllabus content. Some books that she is reading and the professional culture of her school strengthen her conviction that her ideas have a broad social support.

When the task related to the concept of percent was explored, Alice felt that it involved quite simple values and that the students could do it without using the calculator. However, in doing this task, the students spent a lot of time doing computations and lost completely sight of the question. Her objective of working with students the concept of percent failed. At the end of class, on her reflection, she says, "I did not even thought about it, and we lost more of the time with the computations than with the situation". In her later reflection about this episode, Alice 
starts showing some doubts about the use of the calculator. Yet, she does acknowledge that her "resistance" is very strong:

I still think that, at least at this age, [the students] still have to develop the computation skill, isn't it? It is not now or never. (...) It seems that there is nothing else we can do and, therefore, I have this strategy to insist to see if it picks up.

Strengthening convictions. Still another teacher, Clara, reveals no difficulties or resistance regarding the use of a calculator. She says that her pre-service teacher education was crucial to recognizing the importance of working with this instrument. In addition, some meetings of the Portuguese Association of Teachers of Mathematics that she attended early in her career gave her an opportunity to reflect and to learn tasks with which she may use the calculator in the classroom and that was crucial in order to still use it regularly. There seems to be easily swayed by peers who present arguments that she considers do not have mathematical consistency. Despite using a calculator regularly, she wonders about its utility when she thinks in using a task for the first time. Unlike other teachers, she finds that the use of a calculator in the classroom means a profitable use of time that would be otherwise spent on computations and thus can be channeled into other aspects such as reasoning.

This teacher claims to have enjoyed the reflection moments based on the tasks proposed in this course. She indicates that these moments led her to rethink her practices and to enhance the role of daily reflection, recognizing that she should do it before and after completion of a task by her students. She began to give more importance to such matters as the purpose for which a task is presented, the way she leads students to a particular objective and how a lesson unfolds:

That notion that I have is to think on an activity, but to think of it well and deeply, what I want to do with it, so when I go inside [the classroom] I know very well how I can direct things to reach that objective. I realize that I did not always do it as far as I should, quite frankly. And, besides many other things that the course led me to think, in new and different ways, it made me think that, even just for 10 minutes, I have to re-think things over.

Summary. The course led the teachers to reflect on their practices in different ways. For some, like Clara, it strengthened their conviction that their practices in this field are adequate and that major changes are not justified. For others, like Anabela and Marta, it helped to realize some potential of the calculator in certain types of task as well as ways as this instrument can be used in the classroom. Finally, for others, like Alice, the course seems to have been mainly an opportunity to begin to question their professional practice, without, as yet, any indication of significant change.

\subsection{Teachers' perspectives about the course}

In the interviews and also in their portfolios, the teachers made a positive evaluation of the course. We consider, in particular, the views of the teachers regarding the working processes used in the course and, most especially, their views regarding the environment surrounding discussions and reflections.

Working processes. Most value its practical nature, as they worked in mathematical tasks that they could also use in their classrooms. Anabela, for example, praises the working processes used at the sessions and values the tasks that she regards as "challenges". She thinks that, with the adequate adaptations and simplifications, she may propose in her classes all tasks explored 
at the sessions. Clara appreciates especially the problem solving tasks that, as she says, fascinate her. Also stressed by several teachers is the connection established between what was done in the collective sessions and what happened in the teacher's classroom. For example, Sónia commented: "We did activities [at the sessions] like we were students and [after] tried to transfer our results and reflections to the school".

In the working methods of the course, the teachers also stress the collective discussions. As Alice indicates: "That is the best part, I think that this course was great because of that, it was worthwhile. Where is lecturing? Very little!" At the end of the course, this teacher comments that she enjoys sharing, reflecting and discussing with colleagues:

That discussion on the issues that we deal with here in class, I like to do, I had never done except in [pre-service teacher education] and, okay, I like a lot, precisely because of this, it revives certain things that usually we do not speak schools, as there is no time, sharing of experiences that is so nice and I ... in terms of sharing experiences I think [this] is spectacular.

The emphasis on practical work and on discussions and the value ascribed to teachers' experience as well as to mathematics education literature led some teachers to value the relationship established between theory and practice. For example, for João, the analysis of curriculum documents and research papers on many issues, including the use of the calculator, is a positive aspect of the module: "We contacted with studies and theories of researchers with activities implemented by teachers in their classrooms and with their own students. We reflected on these tasks applied and the responses obtained".

Several teachers recognize substantive learnings about topics and issues in mathematics education. For example, in the beginning of the course, Eva and Victor were receptive to the use of the calculator but only used it in topics highly demanding on calculations (such as area and volume). In their perspective, the course enlarged their knowledge regarding its value in a new topic, rational numbers. Another teacher, Marta stresses the change of perspective about classroom practice that the course may induce in the long term:

[I evaluate the course in a] positive way. I think in many things in life we do not see short term results, so it is with one or two courses that we see results, because many times you note that you are doing things in the lessons that you have learned.

Positive environment. Anabela indicates that the methodology of the course was different from the usual and she appreciated the way it allowed for discussion of ideas and reflection. But she highlights the fact that the ideas were discussed without being imposed by the teacher educator, notably concerning the possible use of the calculator:

[In the course things] were done more to realize the potential of using the calculator here and there... Maybe there makes no sense, on the other [situation] it makes sense to use it. I think that such message was very well conveyed. At least I felt so.

This feature of a respectful environment in the course regarding different perspectives is also underlined by other participants, such as Sónia: “...We did not always agree [with what we hear] but we always respected [all positions]". 
The fact that the course promoted reflection is also pointed by several teachers. For example, Clara indicates that she is very happy with the dynamics of the course, with which she identified herself from the very beginning. She indicates that discussing and reflecting with colleagues is very enriching:

The fact that I was always in very small schools generates a distress, because we want to discuss things... I do not know if I will do this or if I will do that. There are no moments to release the anxiety we have about things and for me this course was... One of the great virtues that it has is that we have discussed and from there we hear the opinion of one, what the other did and we take some notes and... And we can think about the things in a different way.

Clara also values her joint reflections with the supervisor after doing the tasks in her classroom because they helped her to see things differently. This led her to reconsider the kinds of tasks in which the calculator could be used as well as to question the choices that she made at the moment:

I think that with the life that we have, come here, go there, go home, kids, school, work, we sometimes forget that we have to stop for a while and think about things. I think it happens to everyone, it must not be just me. But, okay, I noticed today, when we reflected again on the activity that were to propose about the concept and the different representations of rational numbers, maybe, it was before the course (...) I would do not think about putting the calculator on those kinds of fractions. (...) But now, reflecting back... (...) We had to think a bit about that and maybe it was a situation where I now put... It made us think about things.

Also Eva refers that the discussions following the classes with supervision were important for the development of a reflective attitude:

At the end of the class, I did not see a "critical finger" pointing to my teaching practice. However, the supervisor said that I should question myself about the observations, about the results of the students, about their successes and, most especially, their failures. Without noticing, I begun to dissect a class so strangely similar to so many others, reflecting in order to find answer to my observations.

Summary. The teachers appreciated the format of the course, involving sessions with practical tasks and discussions and observed classes at their schools followed by reflections with the supervisor. But the key that helped them to move forward in their reflection and in their practices was the positive non-imposing and respectful environment with which all positions were considered.

\section{Conclusion}

A wide range of conceptions and practices. The sessions of the calculator module of this inservice teacher education course were very informative about the actual positions of teachers regarding the use of this instrument and also regarding wider issues about mathematics teaching and learning. That happened because the calculator is indeed a "hot issue" in our country and because a stimulating and non-judgmental environment was created in the course that enabled open and lively discussions. These discussions showed that there are a variety of positions of teachers of grades 5-6 regarding the use of the calculator in the mathematics classroom - there are those clearly against it, others with a passive position, allowing students to use it but not 
encouraging this use, and still others who are quite affirmative about the use of this instrument. Symbolic and personal factors (Assude 2006) seem to frame these perspectives. Despite the fact that the calculator is advocated in Portuguese national curriculum documents dating from 1991, the "anti-calculator feelings" seem to be very strong in schools. This shows that there is great distance between the official curriculum orientations and some classroom professional practices.

Social factors (Assude 2006) were also clearly noted, showing the role of the professional culture in framing teachers' practices. For example, the case of Anabela shows that, in an encouraging professional environment (her first school), she is stimulated to carry out practices that she avoids in an adverse environment (her current school). Other teachers, such as Clara, seem to carry out her practice in relative independence from the professional environment of the school, but complain that this environment does not allow for sharing and collective reflection, with negative implications in her practices. Both cases illustrate why sometimes teaching practices do not follow directly from teachers' conceptions (Thompson, 1992).

It is interesting to note that pre-service teacher education appears to have been crucial to lead some teachers (such as Clara and Anabela) to assume a favorable position regarding the use of the calculator. This shows that, despite the well known limitations of pre-service teacher education (Lampert and Ball 1998), it still may play an important role in the conceptions of teachers, notably regarding the use of this instrument. That is, alongside with inservice opportunities, teachers' experiences in preservice training and the culture of schools seem to be key factors in framing teachers views and practices regarding the use of the calculator.

Teacher education to promote change. The major orientations of the course and, in particular, the close relation of the course activities to teachers' practice (Ball and Even 2009; Smith 2001) and the role of reflection (Ball et al. 2005) were well accepted by teachers. The working processes combining information, practice and discussion allowed them to analyze different kinds of tasks in which the calculator may be useful when working with rational numbers. It also provided the opportunity for teachers to carry out tasks, using various strategies, to identify the central mathematical ideas in the tasks, to review students' responses in order to realize how they were understanding and doing mathematics, to think about the questions to ask in face of the most common students' difficulties, in order to enable them to progress. The combination of collective sessions and moments of individual classroom supervision followed by reflection also proved fruitful. A key element of this teaching education program was the no imposing and questioning approach used in collective discussions (notably those regarding the use calculator) that seemed to be effective in encouraging teachers to assume their own positions in front of the group. Rather than reacting to an "official" external position, they were led to think by themselves. Dealing with contradictions and conflict in a positive way (Ponte 2009), stimulated teachers to a deeper reflection of their practice.

The calculator module of this course sought to develop an understanding of issues of mathematics teaching and how students learn (Davis et al. 2009). The module yielded some changes in teachers' knowledge, conceptions and practices. Most, if not all, participants learned about new tasks and ways that the calculator could assist in students' learning, notably when working with rational numbers at grades 5-6. Some teachers reinforced their views regarding the potential of the calculator, whereas others had their convictions challenged and felt that they need to reconsider their position, at least in part. $\mathrm{Al}$ least for teachers who tried out these tasks in their classroom, there was a local change of practice. However, we do not claim that this module provoked by itself, a strong change in teachers' conceptions and practices. We just 
claim that it provided a fruitful way to help teachers to reflect on their conceptions and practices and, if they feel so, embark on a process of changing them.

Towards sustained change. In summary, this study documents some interesting aspects of teachers' professional culture and the influence of pre-service and in-service teacher education processes. In addition, it shows how in-service teacher education focused on practice, based on practical work, discussions, classroom observations and reflections, in a non-imposing environment may contribut to teachers reconsider their views and their practices. However, we must be aware that such teacher education experiences must be extended in time so that teachers can feel supported in their schools. A sustained change of practices in using technology requires specific resources and continued support. This is an important theme in the agenda of curriculum development and in the production of materials to teachers, supporting a continued and thorough discussion in schools, and new forms of teachers' collaborative work focused on students' learning.

\section{References}

Assude, T. (2006). Mudanças e resistências na evolução do currículo de Matemática: Estudo de caso sobre as calculadoras na escola primária. In Actas do XV Encontro de Investigação em Educação Matemática (CD-ROM), Monte Gordo.

Ball, D., \& Even, R. (2009). Strengthening practice in and research on the professional education and development of teachers of mathematics: The next steps. In R. Even \& D. Ball, (Eds.), The professional education and development of mathematics teachers (pp. 255-259). New York, NY: Springer.

Ball, D. L., Hill, H., \& Bass, H. (2005). Knowing mathematics for teaching. American Educator, 16(2), 14-18, 46-47.

Bogdan, R., \& Biklen, S. K. (1982). Qualitative research for education: An introduction to theory and methods. Boston, MA: Allyn \& Bacon.

Davis, B., Brown, L. Cedillo, T., Chiocca, C.-M., Dawson, S., Giménez, J., Hodgen, J., Jaworski, B., Kidd, M., \& Siemon, D. (2009). Development of teaching in and from practice. In R. Even \& D. Ball, (Eds.), The professional education and development of mathematics teachers (pp. 149-166). New York, NY: Springer.

Lampert, M., \& Ball, D. L. (1998). Teaching, multimedia, and mathematics. New York, NY: Teachers College Press.

Patton, M. Q. (1987). How to use qualitative methods in evaluation. Newbury Park, CA: Sage.

Perrin-Glorian, M.-J., Deblois, L., \& Robert, A. (2008). Individual practicing mathematics teachers. In K. Krainer \& T. Wood (Orgs.), Participants in mathematics teacher education: Individuals, teams, communities and networks (pp. 111-129). Rotterdam: Sense.

Ponte, J. P. (1992). Concepções dos professores de Matemática e processos de formação. In J. P. Ponte (Ed.), Educação matemática: Temas de investigação (pp. 185-239). Lisboa: IIE.

Ponte, J. P. (2009). External, internal and collaborative theories of mathematics teacher education. In M. Tzekaki, M. Kaldrimidou \& H. Sakonidis (Eds.). Proceedings of the 
33rd Conference of the International Group for the Psychology of Mathematics Education (Vol. 1, pp. 99-104), Thessaloniki, Greece.

Ponte, J. P., \& Chapman, O. (2006). Mathematics teachers' knowledge and practices. In A. Gutierrez \& P. Boero (Eds.), Handbook of research on the psychology of mathematics education: Past, present and future (pp. 461-494). Roterdham: Sense.

Ponte, J. P., \& Chapman, O. (2008). Preservice mathematics teachers' knowledge and development. In L. English (Ed.), Handbook of international research in mathematics education (2nd ed., pp. 225-263). New York, NY: Routledge.

Roth, W.-M. (2005). Doing qualitative research. Rotherdam: Sense.

Ruthven, K. (2009). Towards a calculator-aware number curriculum. Mediterranean Journal of Mathematics Education, 8(1), 111-124.

Serrazina, M. L., Canavarro, A. P., Guerreiro, A., Rocha, I., Portela, J., \& Saramago, M. J. (2005). Programa de formação contínua em Matemática para professores do $1 .^{\circ}$ ciclo (avaliable at http://www.eb1 mat.min-edu.pt/acerca.htm).

Smith, M. S. (2001). Practice-based professional development for teachers of mathematics. Reston, VA: NCTM.

Swan, M. (2001). Dealing with misconception in mathematics. In P. Gates (Ed.) Issues in mathematics teaching (pp. 147-165). London: Routledge Falmer.

Thompson, A. G. (1992). Teachers' beliefs and conceptions: A synthesis of the research. In D. A. Grouws (Ed.), Handbook of research in mathematics teaching and learning (pp. 127-146). New York, NY: Macmillan. 
Table 1 - Sketch of sessions of the calculator module

\begin{tabular}{|c|c|c|c|}
\hline Session & Topics & Activities / Issues adressed & Role of the calculator \\
\hline 1 & $\begin{array}{l}\text { Number sets along the school levels: From } \\
\text { to } \Re \text {, an historical perspective; } \\
\text { Exploring errors: Didactical approaches; } \\
\text { - Rational numbers in grades 5-6 (1991 } 2007 \\
\text { syllabi. }\end{array}$ & $\begin{array}{l}\text { - Teaching approaches to rational numbers; } \\
\text { - Different computational procedures (mental, written } \\
\text { and using the calculator). }\end{array}$ & $\begin{array}{l}\text { - As a source of problems and exercises; } \\
\text { - As a computation instrument; } \\
\text { - As an instrument which we may understand } \\
\text { its inner working. }\end{array}$ \\
\hline 2 & $\begin{array}{l}\text { - Teaching and learning rational numbers; } \\
\text { - Rational numbers as a part-whole, quotient, } \\
\text { operator, ratio, and measure. }\end{array}$ & $\begin{array}{l}\text { - Different tasks, taking into account the different } \\
\text { meanings of rational numbers, the different } \\
\text { computational procedures and the teacher's role. }\end{array}$ & $\begin{array}{l}\text { - To reinforce knowlegde about writing } \\
\text { natural and decimal numbers; } \\
\text { - In the development of number sense. }\end{array}$ \\
\hline 3 & - Representations of rational numbers. & $\begin{array}{l}\text { - Investigating regularities associated to rational } \\
\text { numbers. }\end{array}$ & - To support exploring numerical phenomena. \\
\hline 4 & $\begin{array}{l}\text { - Number sense and operation sense; } \\
\text { - Operations with rational numbers in the } 2007 \\
\text { syllabus; } \\
\text { - Teaching and learning operations with } \\
\text { rational numbers. }\end{array}$ & $\begin{array}{l}\text { - Analyzing the methodological orientations and the } \\
\text { specific objectives of the new syllabus regarding } \\
\text { numbers and operations; } \\
\text { - Analyzing the operations in a perspective directed } \\
\text { towards mental computation and estimation and } \\
\text { emphasizing the meaning of operations. }\end{array}$ & $\begin{array}{l}\text { - As an aid in estimating and mental } \\
\text { computation; } \\
\text { - In understanding operations. }\end{array}$ \\
\hline
\end{tabular}

